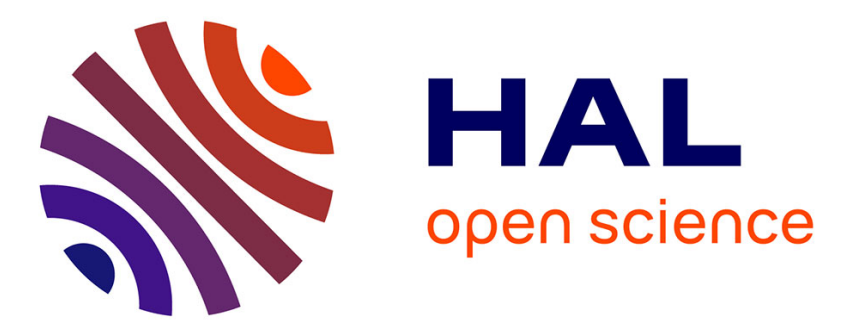

\title{
ULTRA-WIDEBAND BANDPASS FILTERS USING MULTILAYER SLOT COUPLED TRANSITIONS
}

\author{
Mourad Nedil, Tayeb Denidni, Azzeddine Djaiz, Halim Boutayeb
}

\section{To cite this version:}

Mourad Nedil, Tayeb Denidni, Azzeddine Djaiz, Halim Boutayeb. ULTRA-WIDEBAND BANDPASS FILTERS USING MULTILAYER SLOT COUPLED TRANSITIONS. Journal of Electromagnetic Waves and Applications, 2008, 22, page 501-516. hal-00165655

\section{HAL Id: hal-00165655 https://hal.science/hal-00165655}

Submitted on 27 Jul 2007

HAL is a multi-disciplinary open access archive for the deposit and dissemination of scientific research documents, whether they are published or not. The documents may come from teaching and research institutions in France or abroad, or from public or private research centers.
L'archive ouverte pluridisciplinaire HAL, est destinée au dépôt et à la diffusion de documents scientifiques de niveau recherche, publiés ou non, émanant des établissements d'enseignement et de recherche français ou étrangers, des laboratoires publics ou privés. 


\title{
ULTRA-WIDEBAND BANDPASS FILTERS USING MULTILAYER SLOT COUPLED TRANSITIONS
}

\author{
M. Nedil, T. A. Denidni, A. Djaiz, and H. Boutayeb \\ INRS-EMT, University of Quebec \\ 800 rue de la Gauchetiere, Montreal Quebec H5A 1K6, Canada
}

\begin{abstract}
New Ultra-Wideband (UWB) bandpass filters are proposed and tested. The filters are composed of two microstrip Conductor-Backed Co-Planar Waveguide (CBCPW) transitions and a multiple-mode resonator, constituted by a line section. The both cases, where the line section is a microstrip or a CBCPW are tested. First, simulated and experimental results for the transition are presented, showing that a wide operating band is obtained. Then, the results for the proposed filters that use this transition structure are presented. Simulated and measured data show that the filters can provide an operating band from $3.1 \mathrm{GHz}$ to $10.6 \mathrm{GHz}(-10 \mathrm{~dB}$ bandwidth), which is suitable for ultra-wideband systems. The group delay is about $0.3 \mathrm{~ns}$ over the most central band and less than $0.45 \mathrm{~ns}$ all over the operating band. In addition, using an optimization procedure, a bandwidth of $15 \mathrm{GHz}$ can be achieved with the proposed filter which is more than what was fixed by Federal Communications Commission (FCC) for UWB radio systems. Moreover, a filter constituted by combining the two proposed filters was also designed and fabricated, to improve further the band rejection.
\end{abstract}

\section{INTRODUCTION}

Ultra-Wideband (UWB) radio technology has been getting more popular for high-speed wireless connectivity applications, since the Federal Communications Commission (FCC)'s decision to permit the unlicensed operation band from 3.1 to $10.6 \mathrm{GHz}$ in 2002 [1]. UWB radio systems are very promising, because transmission data rates greater than those of other wireless LAN systems can be obtained with low power dissipation. In this area, various studies are under progress [2-7]. UWB filters, which are among the most important passive components, should satisfy the following requirements. These filters 
should satisfy the following requirements: low insertion loss over the operating band, good band rejection, and small group delay variation, which is important for impulse-radio systems.

Conventional filter design procedure is adequate only for relatively narrowband filters, but it is not suitable for wideband filters [8-12]. However, the most major challenge is to design an ultra-wideband filter with about $110 \%$ bandwidth, which makes some usual techniques for broadband designs inefficient. In this area, few UWB bandpass filters have been proposed [13-16]. In [13], dual-mode resonators have been used, whereas in [14], a broadside coupled microstrip to coplanar filter has been reported. Another ultra-wideband bandpass filter with a shielded multi-layered structure has been proposed [15]. However, this filter does not cover all FCC's band. Recently, an UWB filter using Co-Planar Waveguide-to-microstrip transition based on multiple-mode resonators has been introduced [16], but this filter has a moderate group delay and a limited bandwidth due to the transition. To resolve this problem, a slot coupled Conductor-Backed Co-planar Waveguide (CBCPW) to microstrip transition has been proposed recently [17].

In this paper, new UWB bandpass filters are presented. They are based on hybrid microstrip to Conductor-Backed Co-planar Waveguide (CBCPW) transitions. It is shown that the proposed filters offer good performances in terms of band rejection and group delay, and they are suitable for ultra-wideband systems. Furthermore, it is demonstrated that a bandwidth of about $15 \mathrm{GHz}$ can be achieved with this type of filters. A filter constituted by combining the proposed filters was also designed and fabricated, to improve further the band rejection. A good agreement is obtained between simulated and measured results, for the transition and the filters.

\section{MICROSTRIP TO CBCPW TRANSITION}

In this subsection, the Conductor-Backed Co-planar Waveguide (CBCPW)-to-microstrip slot coupled transition used for our design is presented.

Figure 1 shows the geometrical layout of the proposed two-port microstrip-to-CBCPW transition. Referring to Fig. 1a, the transition is characterized by an aperture etched on the common ground plane located between the two-layered structures to provide a fed-through coupling between the upper microstrip and the lower CBCPW lines. In this structure, the upper microstrip conductor is vertically coupled with the central strip conductor of the lower CB-CPW via the aperture as illustrated in Fig. 1.

The transition was designed using commercial software IE3D [18]. 


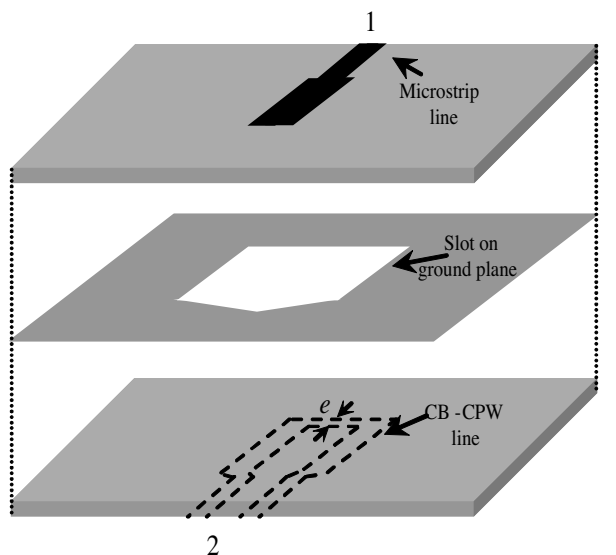

(a)

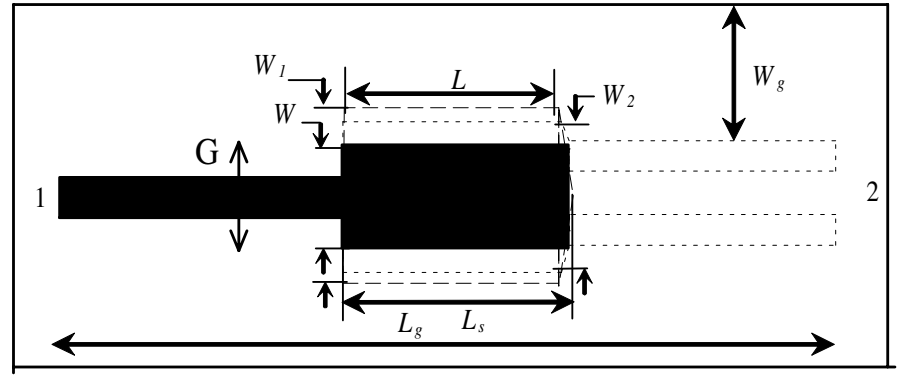

(b)

Figure 1. (a) Layout of the microstrip-to-CB-CPW transition (b) Top view.

The top and bottom $50 \mathrm{Ohm}$ transmission lines were computed using HP's LineCalc. The coupling line widths and line lengths were varied in order to optimize the transition match. It is noted that the coupling mechanism is controlled by the thickness of the substrate and the dimensions of the slot in the common ground plane. Transitions with different slot widths were simulated to optimize the design. Figure 2 shows the S-parameters of the transition for different values of the width $W_{1}$. When the slot coupled width W1 increases from 2.6 to $4.5 \mathrm{~mm}$, the return loss decreases, and the matching and bandwidth increase. From these results, it can be noted that this optimized design offers a good transition and tight coupling between the microstrip feed line to CBCPW-line section. The transition was designed using a Duroid substrate (RT/Duroid 5880) with $r=2.2$ and thickness of 


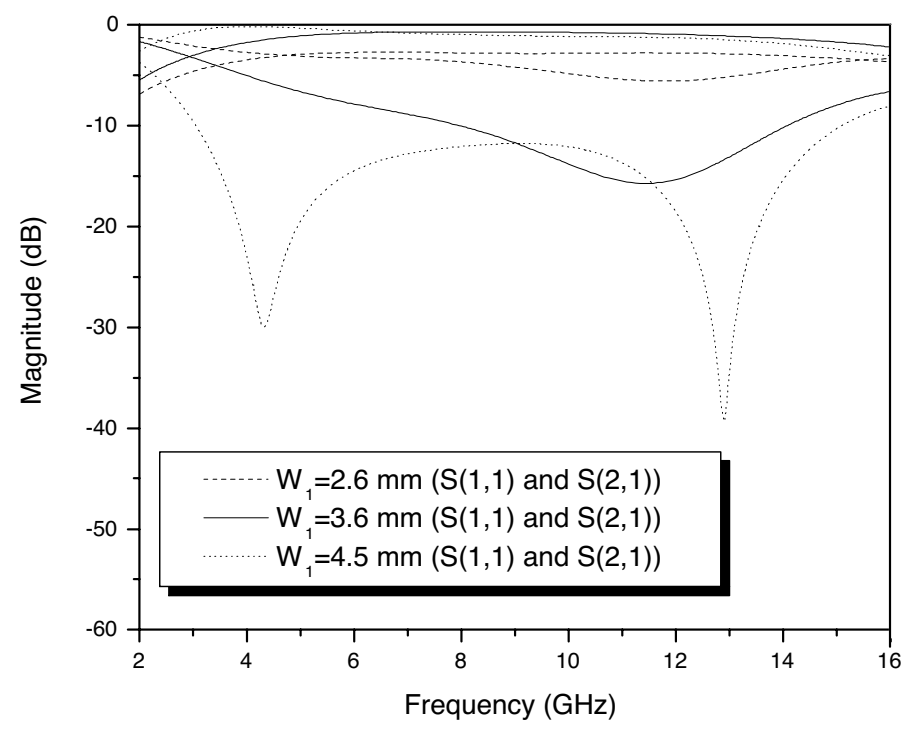

Figure 2. Simulated S parameters of the transition for different values of $W_{1}$.

$0.254 \mathrm{~mm}$. The parameters of the transition are the followings: $L_{S}=$ $5.15 \mathrm{~mm}, L=4.75 \mathrm{~mm}, W=2.7 \mathrm{~mm}, W 1=4.5 \mathrm{~mm}, W 2=4.3 \mathrm{~mm}$, $S=0.2 \mathrm{~mm}, G=0.69 \mathrm{~mm}, e=0.2 \mathrm{~mm}$. The main drawback of the CBCPW technology is the parallel-plate modes, which are considered as unwanted bulk modes [19]. This indicates that the minimum parasitic resonant frequency from the parasitic parallel-plate modes of the $\mathrm{CBCPW}$ can be predicted using a simple rectangular patch model as reported in [19]. The calculated lowest order mode resonance frequency is $f_{11}(20.8 \mathrm{GHz})$ when the width and length of the ground are $W_{g}=5 \mathrm{~mm}$ and $L_{g}=20 \mathrm{~mm}$, respectively. In this case, it can be noted that the leaky-wave phenomenon does not affect the performance of the proposed transition, which allows to avoid the use of via.

To validate the proposed design, a prototype was fabricated and tested. Fig. 3 shows the simulated and measured results. From these, a good agreement is obtained between the simulated and experimental data, and the microstrip-to- CB-CPW transition offers a bandwidth about $12 \mathrm{GHz}$, which is superior than previous results obtained with other transitions [20]. In the next section, this transition was introduced to design a new multi-layer UWB filter with different feed-lines. 


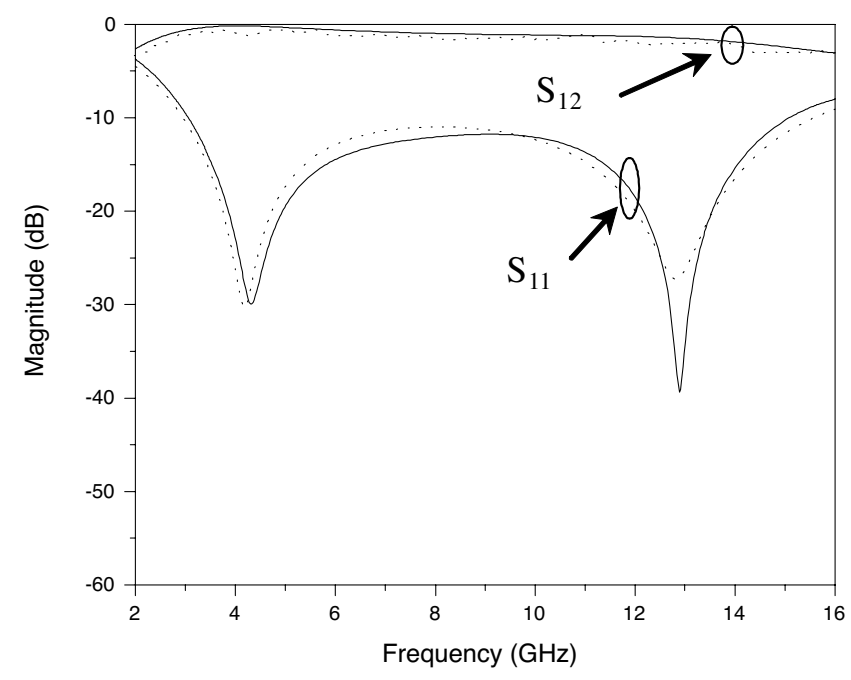

Figure 3. Simulated and measured S parameters of the proposed transition.

\section{FILTER USING CBCPW FEED}

In this section, the proposed filter with CBCPW fed and satisfying the UWB bandwidth requirement $(110 \%)$ is presented.

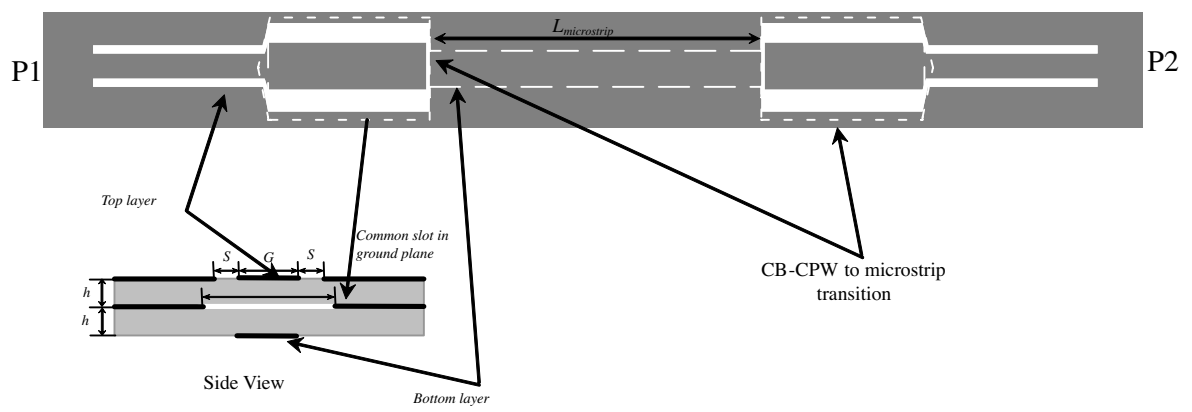

Figure 4. Layout of the CBCPW fed UWB filter.

Figure 4 shows the layout of this filter. The filter is composed of two CBCPW to microstrip transitions, described in the previous section, and a microstrip line section, which acts as a multiplemode resonator (MMR) between the two transitions. At the center 
frequency of pass-band, both side sections of the MMR (CBCPW to microstrip transitions) are identical, and they are chosen as one quarter-wavelength $\left(\lambda_{g} / 4\right)$, while the middle section is set as one half-wavelength $\left(\lambda_{g} / 2\right)$. The filter was simulated using IE3D software. In these simulations, it is found that the out-of-band rejection at high frequencies can be improved by optimizing both CBCPW and microstrip line of the transitions. A parametric study was performed, and the optimized parameters dimensions are the followings: $L_{\text {microstrip }}=15.5 \mathrm{~mm}, L=7.8 \mathrm{~mm}, L S=8.1 \mathrm{~mm}, W=$ $1.4 \mathrm{~mm}, W 1=3.13 \mathrm{~mm}, W 2=2.68 \mathrm{~mm}, G=1.83 \mathrm{~mm}, e=0.15 \mathrm{~mm}$

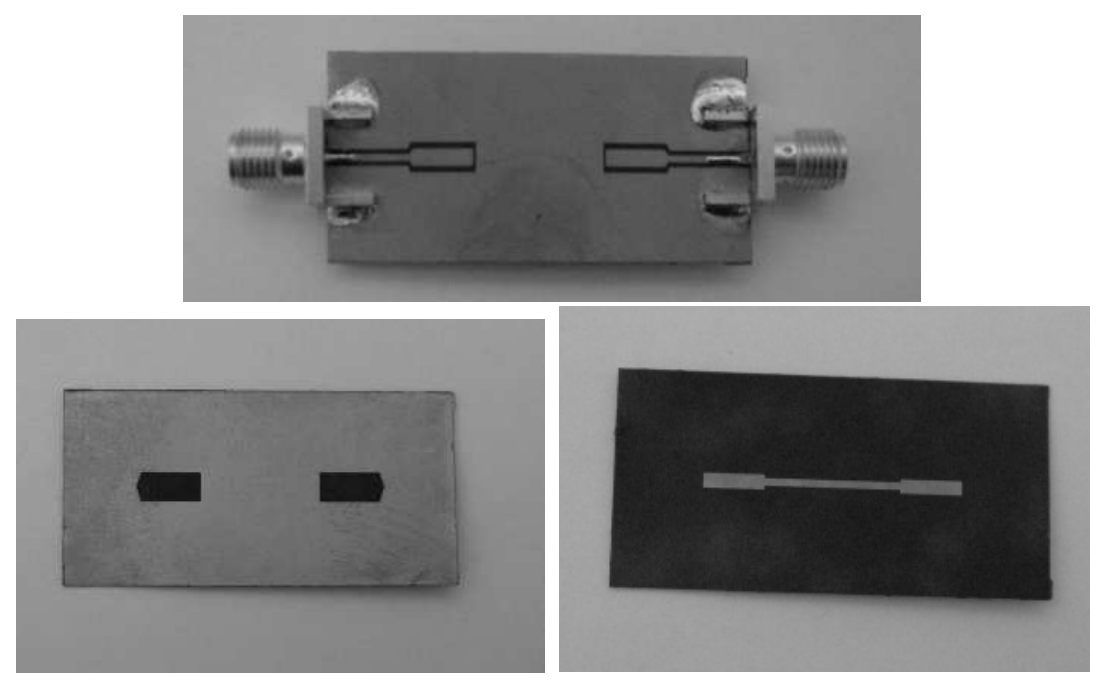

Figure 5. Photograph of the fabricated UWB filter.

Figure 5 shows the photograph of the fabricated filter. The Sparameters were measured using a network analyzer. The simulated and measured results are plotted in Fig. 6, showing that a good agreement is obtained between them. These result show also that the the insertion loss is small. Fig. 7 shows the simulated insertion loss and the return loss magnitude of the UWB filter over a wide frequency range $(1-13 \mathrm{GHz})$ with different coupling lengths $(L=0.5$, 2.8 , and $7.8 \mathrm{~mm}$ ). From these results, for $L=0.5$ and $2.8 \mathrm{~mm}$, it can be seen that three resonant frequencies were generated. When $L=7.8 \mathrm{~mm}$, which is approximately $\lambda_{g} / 4$, at the center frequency of the UWB band $(6.85 \mathrm{GHz})$, the magnitude curve of $S_{21}$ achieves a flat frequency response near the $0 \mathrm{~dB}$ line over the desired band $(3.1-10.6 \mathrm{GHz})$. This indicates that the coupling enhancement of both 


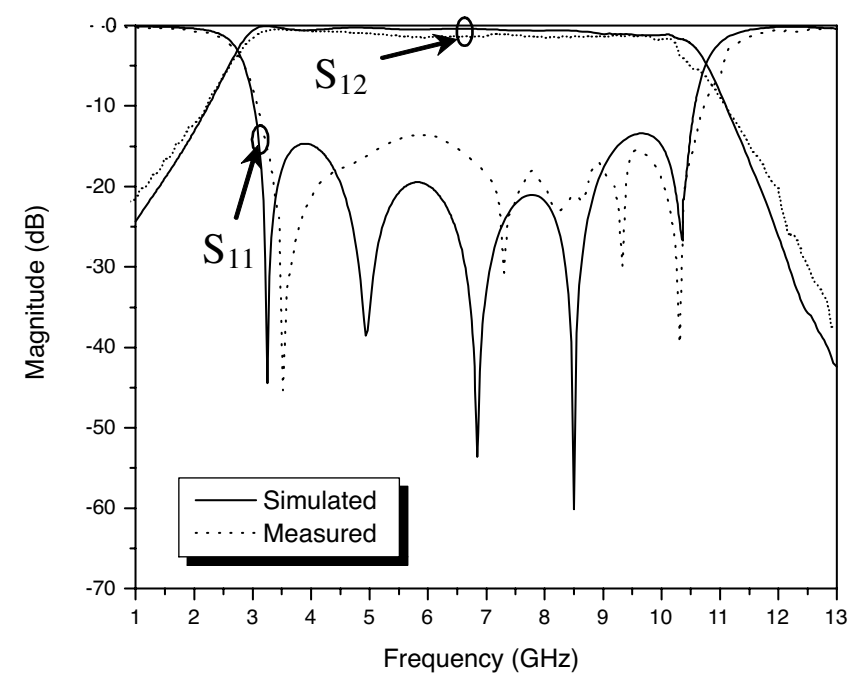

Figure 6. Simulated and measured S parameters of the filter.

both transitions allows to generate other modes in the filter structure, which makes $S_{12}$ response flat in the UWB band. Meanwhile, the return loss is lower than $-15 \mathrm{~dB}$.

Fig. 8 shows the simulated and measured results of the group delay. The group delay varies between $0.3 \mathrm{~ns}$ and $0.5 \mathrm{~ns}$ with a maximum variation of $0.2 \mathrm{~ns}$, which leads to good linearity of the proposed UWB filter. The group delay of the proposed filter is found to be lower than that of the hybrid microstrip/CPW filter reported in [16]. From these results, it can be concluded that the proposed filter satisfies the requirements of a small and flat group delay over the operating band, which is strongly required for impulse radio systems to minimize the distortion in short pulse transmission system.

The transition parameters affect the behavior of the filter considerably. Because the bandwidth of the transition is about $12 \mathrm{GHz}$, it is possible to increase further the bandwidth of the filter. We found that a wider bandwidth may be achieved by optimizing the parameters of the microstrip-CBCPW transitions and the microstrip line. The optimized dimensions are the followings: $L_{\{}$microstrip $\}=8.1 \mathrm{~mm}, L$ $=5.2 \mathrm{~mm}, L_{S}=5.5 \mathrm{~mm}, W=3.1 \mathrm{~mm}, W 1=4.8 \mathrm{~mm}, W 2=4.68 \mathrm{~mm}$, $G=4.5 \mathrm{~mm}, e=0.15 \mathrm{~mm}$. The simulation results of the optimal UWB filter are shown in Fig. 9. It can be seen that a bandwidth improvement is achieved by comparison with the results plotted in Fig. 3. The obtained bandwidth is about $15 \mathrm{GHz}$, which is wider than 


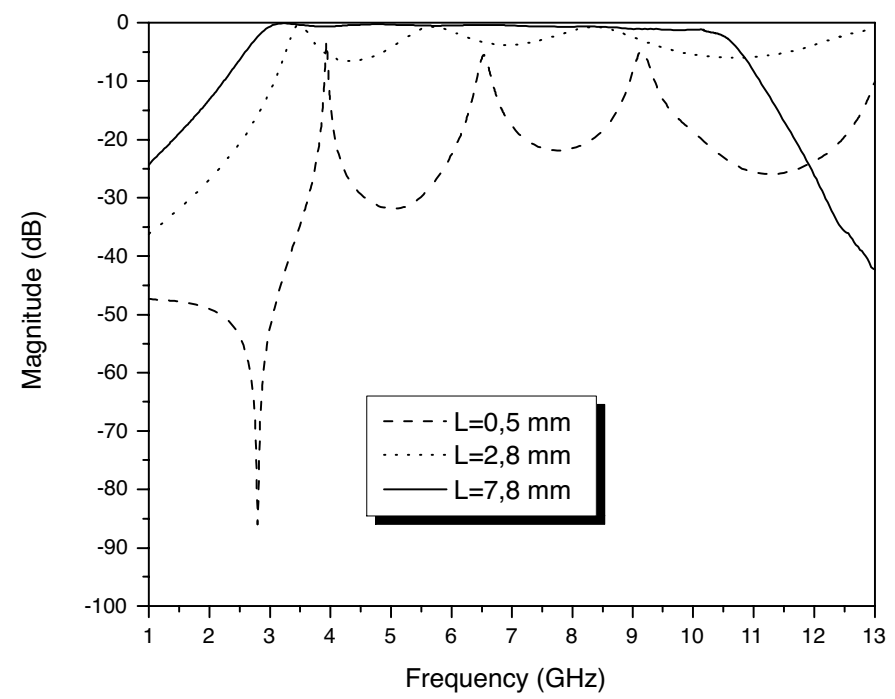

(a)

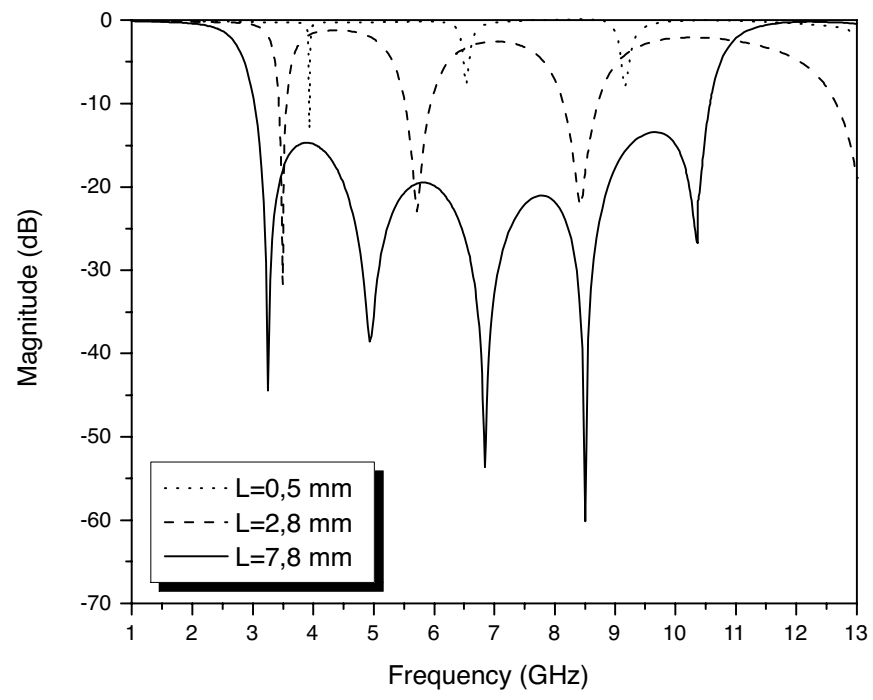

(b)

Figure 7. Simulation results of the filter for different values of $L$. (a) Insertion loss, (b) Return loss. 


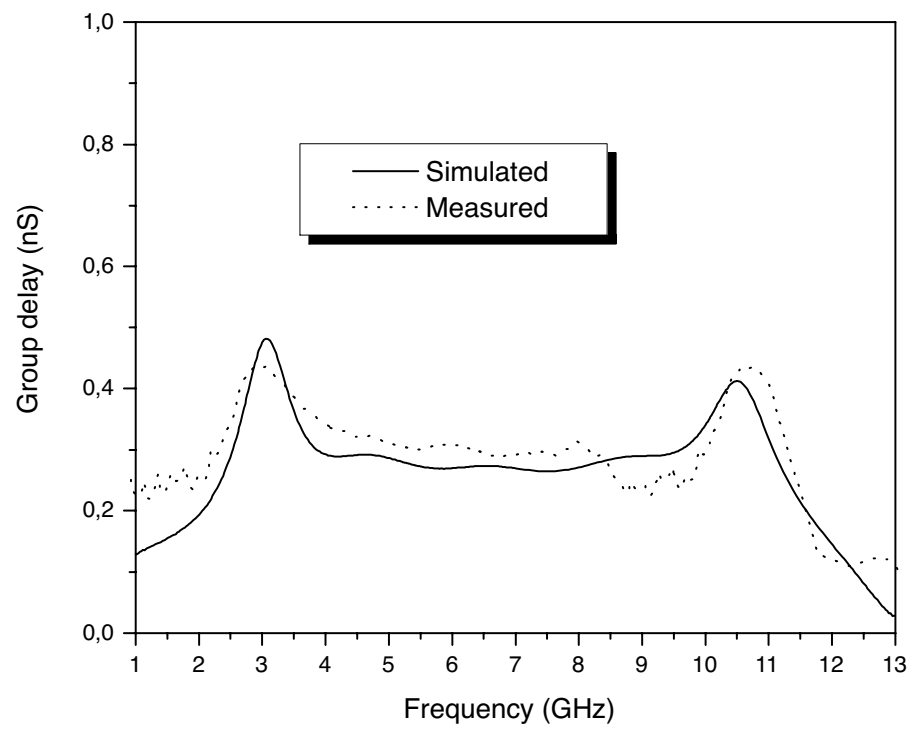

Figure 8. Simulated and measured group delays.

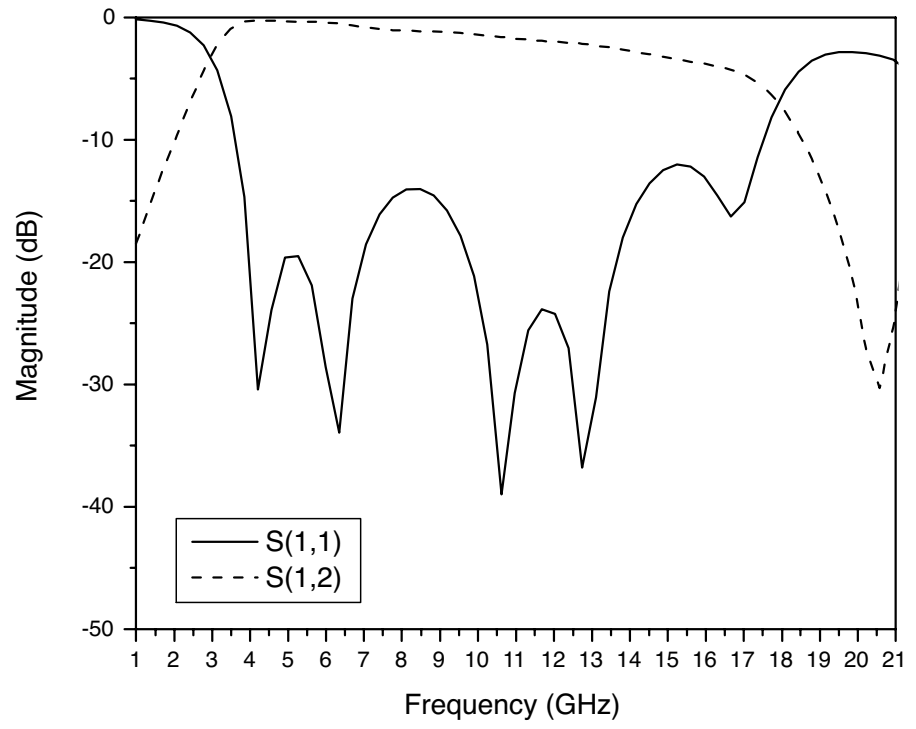

Figure 9. Simulated S parameters the filter with optimum bandwidth. 
the bandwidth fixed by FCC.

In the next section, we present another type of UWB filter with microstrip-line feed.

\section{FILTER USING MICROSTRIP-LINE FEED}

A filter composed of two microstrip-CBCPW transitions and a section of CBCPW transmission line was designed. The CBCPW feed line and the microstrip line are replaced by microstrip feed line and a section of CBCPW, respectively to generate the multi-mode resonator (MMR). At the central frequency of the concerned UWB passband, the two side sections of this MMR are equally selected as one quarter-wavelength while the central section is set as one half-wavelength $\left(\lambda_{\{g 0\}} / 2\right)$ long. From this, the second resonant frequency of this MMR can be fixed around $6.85 \mathrm{GHz}$. According to numerical analysis, the out-of-band rejection at high frequencies can be improved by optimizing both the microstrip/CBCPW transition and the microstrip. The following optimized parameters were obtained: $L_{\{C P W\}}=16.2, L=7.8 \mathrm{~mm}$, $L_{S}=8.3 \mathrm{~mm}, W=1.0 \mathrm{~mm}, W_{1}=3.15 \mathrm{~mm}, W_{2}=2.68 \mathrm{~mm}$, $G=1.4 \mathrm{~mm}, e=0.15 \mathrm{~mm}$.

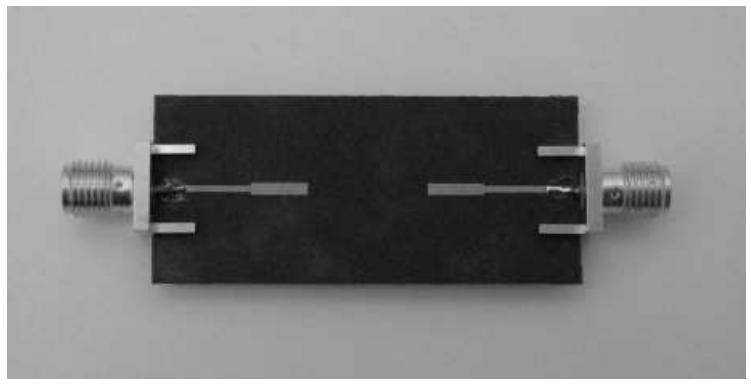

Figure 10. Filter with microstrip-line feed.

The fabricated filter is illustrated in Fig. 10. The simulated and measured results are shown in Fig. 11. It can be seen that the measured results agree well with the simulated ones. The results show that a smaller insertion loss is obtained with this filter than for the previous filter.

Fig. 12 shows the simulated insertion loss and return loss magnitude of the second UWB filter over the wide frequency range $(1.0-13.0 \mathrm{GHz})$ for three different coupling lengths $(L=0.8,2.8$ and $7.8 \mathrm{~mm}$ ). For $L=0.1$ and $2.8 \mathrm{~mm}$, the three resonant frequencies can be clearly seen to be almost equally spaced within the UWB pass-band. 


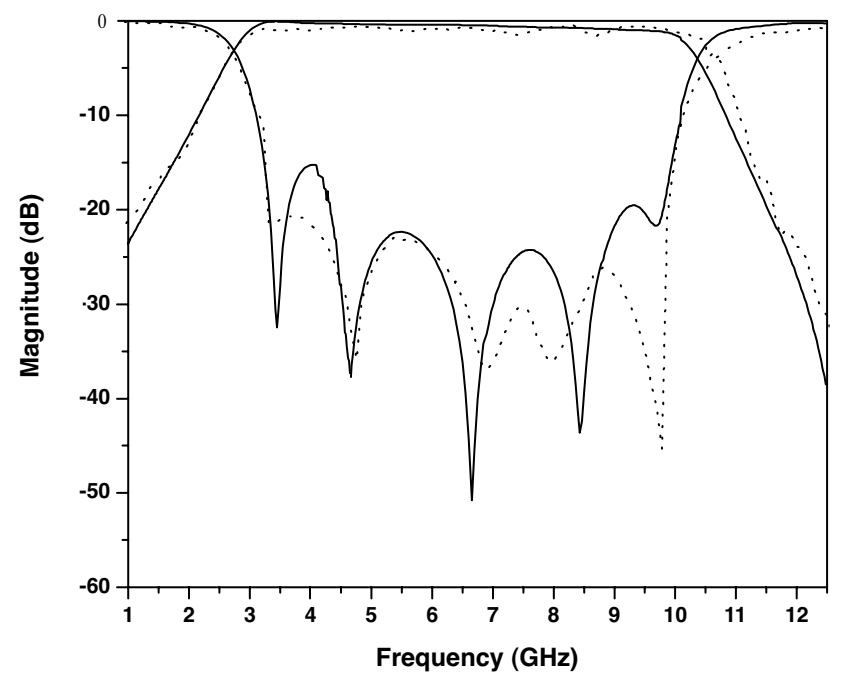

Figure 11. Simulated and measured results of the filter with microstrip-line feed.

For $L=7.8 \mathrm{~mm}$, the $S_{2} 1$-magnitude in the two regions among the three peaks moves up so as to realize an almost flat frequency response near the $0 \mathrm{~dB}$ line over the desired band $(3.1-10.6 \mathrm{GHz})$. These results demonstrate that for the both UWB filters, the structure of CBCPW/microstrip transitions and microstrip or CBCPW section lines allow to generate an MMR to design an UWB filter.

The simulated and measured group delays are plotted in Fig. 13, a small value is obtained (0.3 ns).

\section{COMBINATION OF THE TWO FILTERS}

To improve further the band rejection in low frequencies, the previous filters are combined as illustrated in Fig. 14. This design allows to increase the number of pole. After a numerical study, we obtained the following optimized parameters: $L_{\{C P W\}}=13.8 \mathrm{~mm}$, $L\{$ microstrip $\}=15.3 \mathrm{~mm}, L_{S}=8.2 \mathrm{~mm}, L=7.8 \mathrm{~mm}, W=1.46 \mathrm{~mm}$, $W_{1}=3.2 \mathrm{~mm}, W_{2}=2.6 \mathrm{~mm}, W_{3}=1.4 \mathrm{~mm}, G=1.6 \mathrm{~mm}$.

Figure 15 shows the simulated results of both insertion loss and reflection loss of the global filter. From these curves, the out-of-band rejection level is about $-55 \mathrm{~dB}$ at $1 \mathrm{GHz}$ and $-50 \mathrm{~dB}$ at $13 \mathrm{GHz}$, the pass-band is ultra-wide from 3.1 to $10.6 \mathrm{GHz}$ ( $-10 \mathrm{~dB}$ bandwidth), the 


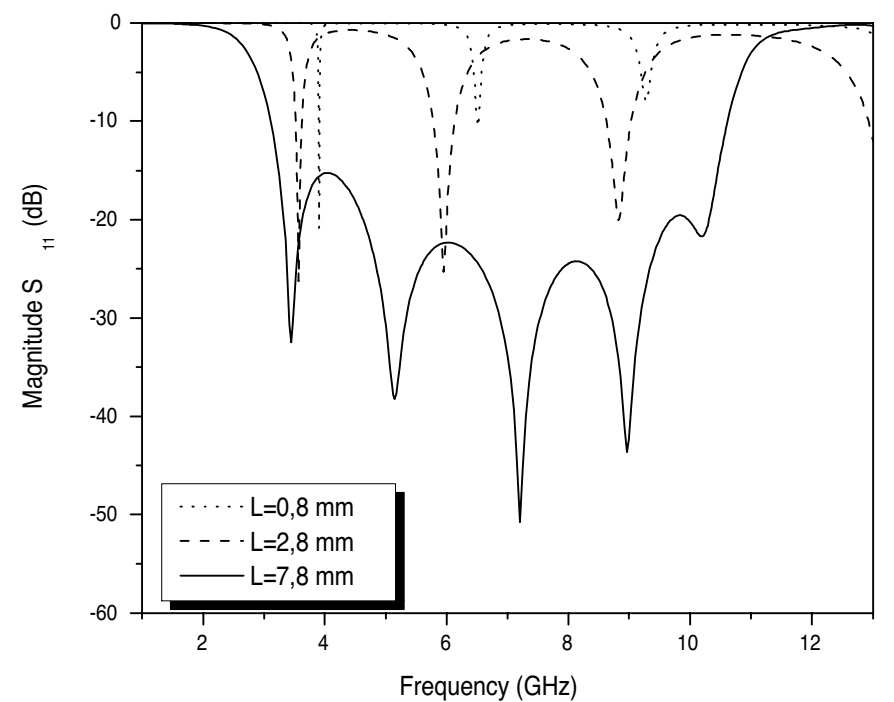

(a)

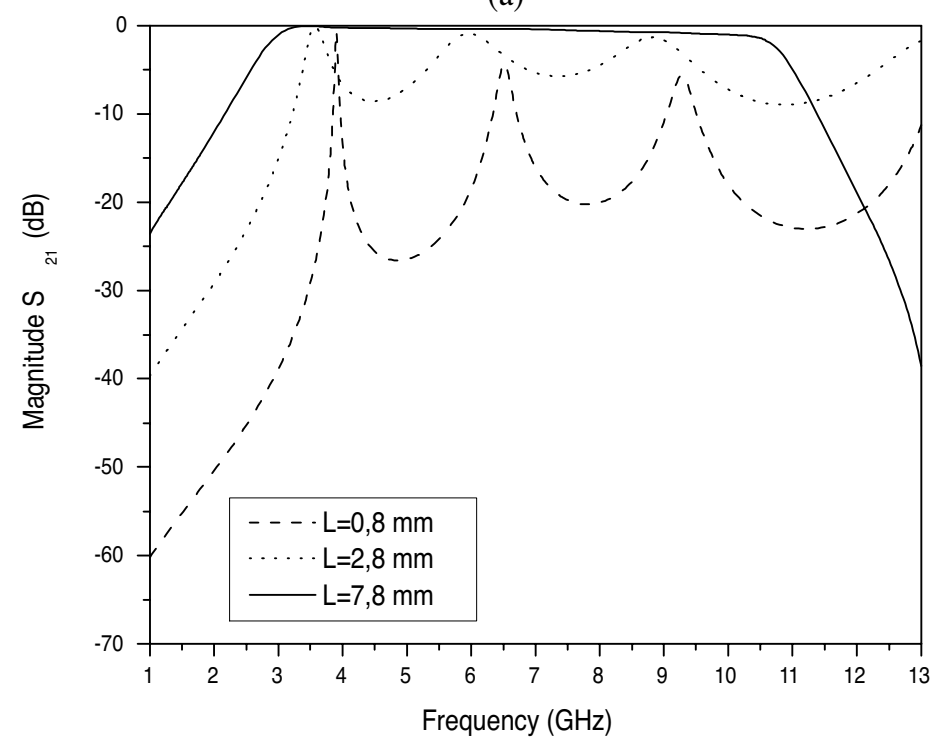

(b)

Figure 12. Simulation results of the filter for different values of $L$ (a) Insertion loss (b) Return loss. 


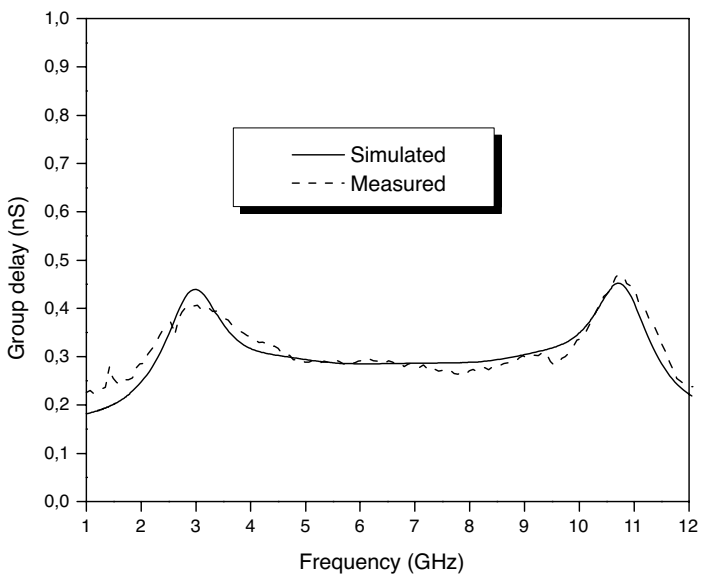

Figure 13. Simulated and measured group delay of the filter.

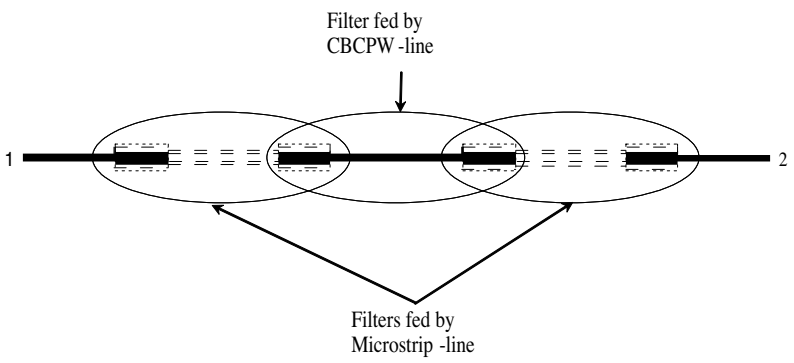

Figure 14. Layout of the filter made by combining two types of filters.

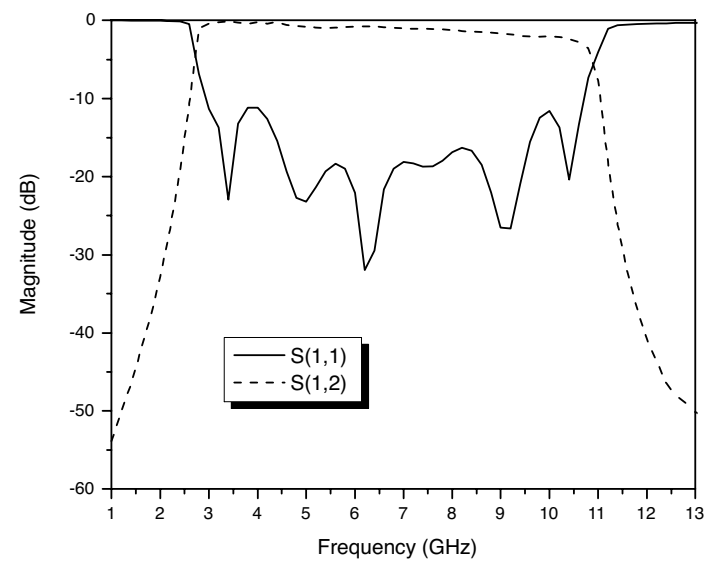

Figure 15. Simulated S parameters of the filter. 


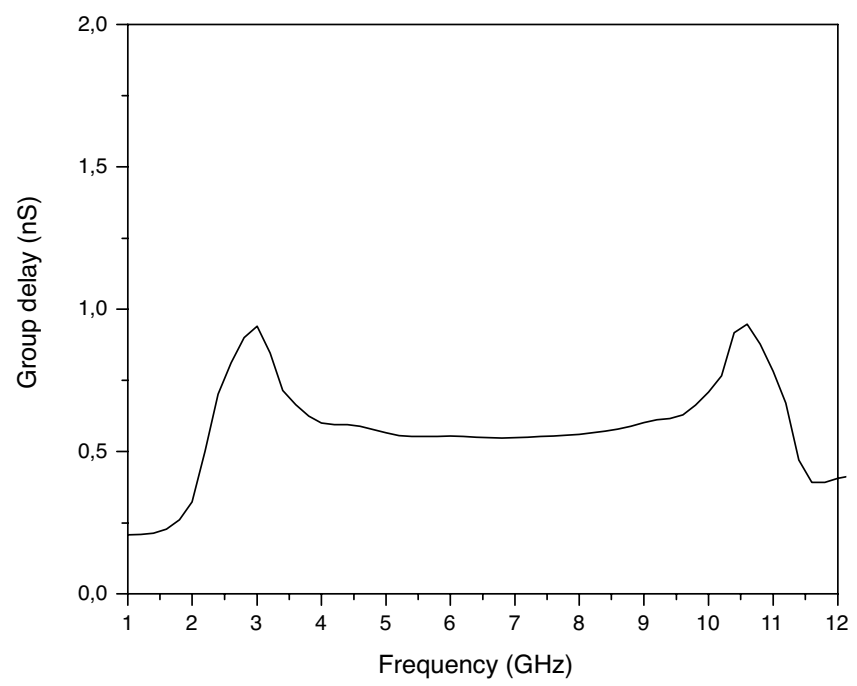

Figure 16. Simulated group delay.

insertion loss is very low and flat, and the reflection coefficient is less than $-12 \mathrm{~dB}$. The simulated group delay response of the global filter is plotted in Fig. 16. At the middle-band, the group delay is about $0.5 \mathrm{~ns}$, and its maximum variation in the pass-band is around $1 \mathrm{~ns}$.

\section{CONCLUSION}

New UWB filters using a back-to-back microstrip to CBCPW transition have been presented. First, it has been shown that the transition can offer a wide-band of $12 \mathrm{GHz}$. Then, UWB filters with different feed lines have been designed and tested, showing that these filters have low insertion loss, good band rejection, high return loss, small group delay variation, and can operate in the band $3.1-10.6 \mathrm{GHz}$, which is suitable for UWB wireless systems. In addition, by cascading multiple filters, it has been demonstrated that the band rejection can be improved further.

\section{ACKNOWLEDGMENT}

This work was supported in part by National Science Engineering Research Council of Canada (NSERC). 


\section{REFERENCES}

1. Revision of part 15 of the Commission's Rules Regarding UltraWideband Transmission Systems, First note and order Federal Communications Commission, ET-Docket, 98-153, Feb. 2002.

2. Geran, F., G. Dadashzadeh, M. Fardis, N. Hojjat, and A. Ahmadi, "Rectangular slot with a novel triangle ring microstrip feed for UWB applications," Journal of Electromagnetic Waves and Applications, Vol. 21, No. 3, 387-396, 2007.

3. Fan, Z. G., L. X. Ran, and J. A. Kong, "Source pulse optimizations for UWB radio systems," Journal of Electromagnetic Waves and Applications, Vol. 20, No. 11, 1535-1550, 2006.

4. Sadat, S., M. Houshmand, and M. Roshandel, "Design of a microstrip square-ring slot antenna filled by an H-shape slot for UWB applications," Progress In Electromagnetics Research, PIER 70, 191-198, 2007.

5. Kharakhili, F. G., M. Fardis, G. Dadashzadeh, A. A. K. Ahmad, and N. Hojjat, "Circular slot with a novel circular microstrip open ended microstrip feed for UWB applications," Progress In Electromagnetics Research, PIER 68, 161-167, 2007.

6. Sadat, S., M. Fardis, F. G. Kharakhili, and G. Dadashzadeh, "A compact microstrip square-ring slot antenna for UWB applications," Progress In Electromagnetics Research, PIER 67, 173-179, 2007.

7. Klemm, M. and G. Troester, "EM energy absorption in the human body tissues due to UWB antennas," Progress In Electromagnetics Research, PIER 62, 261-280, 2006.

8. Xiao, J. K. and Y. Li, "Novel compact microstrip square ring bandpass filters," Journal of Electromagnetic Waves and Applications, Vol. 20, No. 13, 1817-1826, 2006.

9. Alfano, L., A. D'Orazio, M. De Sario, V. Petruzzelli, and F. Prudenzano, "A continuous varying impedance passband microstrip filter exploiting a butterfly wing shape," Journal of Electromagnetic Waves and Applications, Vol. 19, No. 9, 1145$1156,2005$.

10. Zhang, J., J.-Z. Gu, B. Cui, and X.-W. Sun, "Compact and harmonic suppression open-loop resonator bandpass filter with tri-section SIR," Progress In Electromagnetics Research, PIER 69, 93-100, 2007.

11. Zhang, X.-C., Z.-Y. Yu, and J. Xu, "Novel band-pass Substrate Integrated Waveguide (SIW) filter based on Complementary Split Ring Resonators (CSRRS)," Progress In Electromagnetics 
Research, PIER 72, 39-46, 2007.

12. Shen, T. and K. A. Zaki, "Length reduction of evanescent-mode ridge waveguide bandpass filters," Progress In Electromagnetics Research, PIER 40, 71-90, 2003.

13. Ishida, H. and K. Araki, "Design and analysis of UWB bandpass filter with ring filter," IEEE MTT-S Int Microwave Symposium Digest, 1307-1310, 2004.

14. Li, K., D. Kurita, and T. Matsui, "An ultra-wideband bandpass filter using broadside coupled microstrip-coplanar waveguide structure," IEEE MTT-S Int. Microwave Symposium Digest, 675$678,2005$.

15. Tanaka, A. and Y. Horii, "A compact multi-layered ultrawideband bandpass filter with plural transmission zeros and improved out-of-passbands," IEEE MTT-S Int Microwave Symposium Digest, 1229-1232, 2006.

16. Wang, H., L. Zhu, and W. Menzel, "Ultra-wideband bandpass filter with hybrid microstrip/CPW structure," IEEE Microw. Wirel. Compon. Lett., Vol. 15, 844-846, 2005.

17. Nedil, M., T. A. Denidni, and A. Djaiz, "Ultra-wideband microstrip to CB-CPW transition applied to broadband filter," Electronics Letters, Vol. 43, 464-466, April 2007.

18. IE3D 8.2, Zeland Software, Inc., Fremont, CA, USA.

19. Haydl, W. H., "On the use of vias in conductor-backed coplanar circuits," IEEE Trans. on Microwave Theory and Tech., Vol. 50, No. 6, 1571-1577, 2002.

20. Zhu, L. and W. Menzel, "Broad-band microstrip-to-CPW transition via frequency-dependent electromagnetic coupling," IEEE Trans. Microw. Theory Tech., Vol. 52, No. 5, 1517-1522, May 2004. 